\title{
An ergonomics training program for student notebook computer users: \\ Preliminary outcomes of a six-year cohort study
}

Karen Jacobs ${ }^{1}$, Jennifer Kaldenberg ${ }^{2}$, Jackie Markowitz ${ }^{1}$, Ellen Wuest ${ }^{1}$, Miranda Hellman ${ }^{1}$, Amarachi Umez-Eronini, ${ }^{3}$ Michael Arsenault ${ }^{4}$, Bryce Walker ${ }^{5}$, Victoria Hall ${ }^{6}$, Marina Ciccarelli, ${ }^{7}$ Richard Parsons ${ }^{7}$ and Alice Barr ${ }^{8}$

${ }^{1}$ Boston University, College of Health and Rehabilitation Sciences: Sargent College, Department of Occupational Therapy, 635 Commonwealth Avenue, Boston, MA 02215, USA

${ }^{2}$ New England Eye 930 Commonwealth Ave Boston, MA 02215, USA

${ }^{3}$ Boston University Boston University School of Public Health, Boston, MA 02115, USA

${ }^{4}$ Frank H. Harrison Middle School, 220 McCartney St. Yarmouth, ME 04096, USA

${ }^{5}$ Prince George's Community College, Technology Resource Center 301 Largo Road, Largo, MD, 20774 USA

${ }^{6}$ Boston University, College of Arts and Sciences, 725 Commonwealth Avenue, Boston, MA 02115, USA

${ }^{7}$ School of Occupational Therapy \& Social Work, Curtin University, Kent St, Perth, Western Australia 6102, Australia

${ }^{8}$ Yarmouth High School Yarmouth, Maine USA 


\section{Abstract}

Background: The Maine Learning Technology Initiative (MLTI) is a program established in the state of Maine in the United States of America, where all students in $7^{\text {th }}$ and $8^{\text {th }}$ grades are provided with a notebook computer to use at school and at home during the academic year.

Objective: This study aimed to describe the anthropometric measurements, typing proficiency of a cohort of students in the MLTI, and investigate the impact of participatory ergonomics education and use of peripheral notebook accessories on their reported musculoskeletal and visual discomfort. This paper reports the results from the first three years of the study.

Methods: This longitudinal study commenced in 2009 with 34 students in $7^{\text {th }}$ grade consenting to participate for six years through the $12^{\text {th }}$ grade. Students received ergonomics education about healthy notebook use, reinforced with web-based resources; and were provided with peripheral notebook accessories including a notebook riser, and external keyboard (split or non-split) and an external mouse. Results: The use of an external keyboard resulted in a reduction in neck and shoulder pain. Participants self-reported fewer headaches when using an external mouse. Using no external accessories was associated with self-reported back pain. Although other musculoskeletal discomforts decreased over time, the changes were not statistically significant. There was a trend for the reduction of visual symptoms including dry/watery eyes and sore, tired eyes during the study.

Conclusion: Participatory ergonomics training and use of external devices may have significant health benefits for children involved in notebook programs who have daily exposure to this technology for school and leisure purposes. Internal and external validity of the results were limited by small sample size.

Keywords: vision symptoms, longitudinal study, musculoskeletal discomfort, occupational therapy, occupation 


\section{INTRODUCTION}

Computer use has become an everyday occupation for many school-aged children around the world. Nowadays, children use computers for education, leisure pursuits and communication, both in home and school contexts [1, 2]. Schools frequently encourage children to use computers for activities such as word processing, searching for information on the web, using charts, graphs and educational software [3]; with notebooks preferentially used in schools because of their relative inexpensive cost and greater transportability, compared to desktop computers. Recently, the Kaiser Foundation report on American children and adolescents aged 8-18 years identified that young people's ownership of a laptop (or notebook) computer had increased from $12 \%$ in 2004 to $29 \%$ in 2009 [4]. The study found the average daily computer use by children 8-18 years for leisure and social purposes (not including school work) was 2 hours 17 minutes in 2009.

Children and adolescents who use using computers for school work, in addition to leisure activities, both at and away from school, have even higher exposures. Over a decade ago, Harris and Straker reported that among a sample of middle and high school students $(\mathrm{N}=314)$ involved in 1:1 notebook programs in Australian private schools, participants used their notebooks for an average of 3.2 hours per day, with a maximum exposure of 15 hours per day for some students [5]. Mean weekly computer use was reportedly 16.9 hours, to a maximum of 80 hours per week for some students.

While the effects of prolonged computer use in adults have been well documented, less research has been conducted on the effects of computer use on the health and well-being of children and adolescents. Harris and Straker (2000) found that 
$60 \%$ of the high school students in their study experienced discomfort associated with notebook computer use at school. A strong correlation with neck, shoulder, and lower back pain and use of computers and other information technologies was found in a study of Finnish adolescents [6]. Similarly, a direct increase in musculoskeletal discomfort in Irish middle school students after using a computer during classes of 40 to 80 minute durations [7]. The musculoskeletal discomfort associated with computer work spaces in schools has been attributed to design, when furniture, including desks and chairs, are inappropriate for a child's body size [8]. A 2010 study of 537 fifth grade school children (aged 9-11 years) measured children's knowledge of, and attitudes towards healthy computing [9]. Forty per cent of the students reported discomfort associated with computer use, but lacked the knowledge about how to appropriately respond to the discomfort. The study found that while the school children had sufficient knowledge of basic ergonomic principles related to the set-up of their computer workstations, they were restricted in translating this knowledge into practice, because of of non-adjustable and ill-fitting furniture at school and home. Children using computers at workstations not specifically designed for computer use are 1.89 times more likely to experience musculoskeletal discomfort compared to children when using furniture specifically designed for computing [10]. Discomfort has also been associated with the transportation of notebook computers to and from school. Harris and Straker (2000) found that $61 \%$ of students in their study reported discomfort associated with carrying their notebook computers. Musculoskeletal problems experienced in childhood may persist and result in a chronic musculoskeletal disorder in adulthood [11, 12]. 
Visual health complaints have also been associated with computer use.

Computer Vision Syndrome (CVS) has been found among adult computer users and is characterized by symptoms including eyestrain; blurred vision; temporary myopia; dry and irritated eyes; photophobia; double vision, and headaches [13]. Although CVS has not yet been identified among child computer users in the research literature, there is evidence to suggest that school children experience visual discomfort associated with exposure to computer use and when working at poorly designed workstations $[5,10$, 11]. Additionally, the visual systems of children are still developing, and therefore they may be more susceptible to injury than adult computer users [14].

The benefits of computer accessories (e.g. external mouse and keyboard) on musculoskeletal discomfort have been addressed in previous research with adult populations in the workplace. The use of external accessories, including a mouse, keyboard and visual display, has been associated with decreased discomfort in comparison to a stand-alone notebook computer $[15,16]$. Although research has investigated the effects of peripheral computer accessories for adults, similar research has not yet been conducted to determine the effect of computer peripherals, and in particular, using a split keyboard, on musculoskeletal health among children and adolescents.

Education about appropriate workstation design was found to be a positive intervention in diminishing discomfort and pain in middle school students [17], and reducing computer-related visual symptoms in adult users $[18,19]$. Despite the health benefits of ergonomics education among child computer users, many parents and teachers appear unaware of the adverse physical health effects of children's computer 
use. Studies investigating the amount of training in computer ergonomics, found an overwhelming majority of teachers had received no formal training and did not possess the skills to promote healthy computer use among their students, despite requiring them to use computers to complete assigned school work and homework [8, 20]. A study by Kimmerly and Odell (2008) reported that parents are not primarily concerned with potential musculoskeletal discomfort among their children due to computer use. Instead, parents focused their concern on types of computing activities, such as chat rooms and social networking sites [21]. Similarly, the majority of the school children in the study by Tran and Ciccarelli (2012) reported they did not know if their parents or teachers were concerned about their physical or visual health related to their use of computers. These findings suggest insufficient communication about healthy use of computers by the adults in these children's lives; even though they are in a position to positively influence the children's computing behaviours [9].

A series of evidence-based guidelines to prevent musculoskeletal symptoms in children using computers was recently published [22]. These guidelines included recommendations for appropriate body mechanics when using and transporting a notebook computer. It is important to create a suitable physical environment that is appropriate to the child's body size and promotes healthy computer use. It is recommended that schools purchase adjustable furniture, so workstations can be individually adjusted for every child so that both feet are supported and the amount of head or neck flexion required to view the screen is minimized [22]. Variation of tasks, postures and muscle activity has also been recommended to reduce the risk of musculoskeletal discomfort [23, 24]. Children reportedly ignore discomfort when 
engaged in computer-based activities [25], so regular breaks should be encouraged among children using computers; however middle school children are less aware of the importance of postural and task variation as a means of promoting musculoskeletal health compared to their knowledge of computer workstation set-up [9]. When transporting notebook computers, researchers agree that the child should carry the notebook in a comfortable backpack with two shoulder straps [26] and limit the total weight of the bag to approximately $10 \%$ of the child's body weight [27].

The Maine Learning Technology Initiative (MLTI) was established to prepare students in the state of Maine, in the United States of America for a rapidly changing world by providing students and teachers to work collaboratively with technology on a 1 to 1 basis. In 2002, the state government provided each student in $7^{\text {th }}$ and $8^{\text {th }}$ grades with a notebook computer to use at school and at home; and some towns elected to provide students with notebook computers through the $12^{\text {th }}$ grade. Research around this initiative suggests that this 1:1 notebook initiative has decreased delinquency among these students, increased student participation in class, and improved student-teacher interactions. Students feel that through using the notebook computers the quality of their learning has improved, they better understand what they are learning and they find school more interesting [28]. Though research has been conducted on the effects of the MLTI on scholastic performance, there have been no studies investigating the effects on the musculoskeletal health of these students. The MLTI does not include mandatory training for students in ergonomic principles for healthy notebook use. Even if some school districts elect to include such training, there is currently no standard curriculum. 
This study aimed to investigate the effects of an ergonomics education program on the physical health of the middle school students involved in the MLTI. This paper will provide a summary of our preliminary findings related to reported visual and musculoskeletal symptoms of the MLTI notebook program participants over a three year period, from $7^{\text {th }}$ grade to $9^{\text {th }}$ grade. The planned six-year study will continue until the participants' complete high school $\left(12^{\text {th }}\right.$ grade).

\section{METHODS}

\subsection{Study Design}

This is a six-year prospective cohort study using a repeated measures design. The study commenced at the beginning of the school year in 2009, when the participants were in $7^{\text {th }}$ grade.

\subsection{Study sample}

A convenience sample of students in $7^{\text {th }}$ grade enrolled in a Maine public middle school was recruited for this study. Participants were informed of the study requirements including the requirement that they provide self-report data and undergo direct measurement each year of the study. Informed consent and assent to participate in the study was obtained from the students' parents/guardians and the students, respectively.

For the duration of the study, participants received a $\$ 10$ iTunes gift certificate at the start and conclusion of each academic year, as a token of appreciation for their time. At the conclusion of the study, participants will be allowed to keep the notebook 
accessories and digital camera used in the study. The Institutional Review Board at Boston University provided ethics approval for this study.

\subsection{Ergonomics intervention}

At the start of the study, all participants received face-to-face ergonomics training from the first author, who is an occupational therapist and a board certified professional ergonomist. A variety of evidence-based information sources, including the HewlettPackard Company's Safety \& Comfort Guide (2002) and Healthy Computing Microsoft Hardware's Guide to Ergonomics at Work (2003) were used to develop the content for the training program. This training provided information on how to apply ergonomics principles into the arrangement of notebook computer workstations at home and at school. This included advice to take frequent breaks by looking twenty feet away every twenty minutes for twenty seconds, and to change their postures regularly; and provision of reference diagrams about how to set-up peripheral devices (i.e. notebook riser, external keyboard) to use with the notebook computer.

Each participant also received a mouse pad printed with a diagram portraying correct posture while using a notebook computer and information that included the key principles reinforced during ergonomics training. The concept: "Work in Comfort: Change and Vary Your Posture Often" was reinforced. Students were given access to a website specifically developed for this study that provided information designed to reinforce content from the face-to-face ergonomics training. As participants accessed the website, they were introduced to a speaking avatar named Ergo-Bear, who 
orientated them to the range of ergonomics educational resources available on the website including fact sheets on healthy notebook computing.

\section{INSERT FIGURE 1 HERE}

Participants received a notebook riser (Aidata brand with 15ㅇ / 25ㅇ / 35은 adjustable options) and an external wireless mouse. Participants were randomly assigned to one of two external keyboards for use at home. Participants in group one received a wireless non-split keyboard, and participants in group two received a wireless split keyboard.

\subsection{Study outcomes and outcome measures}

The study investigated a number of outcomes that are described below. Data were measured in different frequencies across five time periods ( $T 1=$ October 2009; $\mathrm{T} 2=$ May 2010; T3= October 2010; T4= May 2011; and T5=October 2011).

(i) Changes in participants' body measurements (height and body mass): these were recorded twice per the participant's academic year during the study. Participants' height was measured using a heavy duty professional tape measure. Body mass was measured using a bathroom scales. Measurements were recorded in imperial measurements (inches and pounds) and converted to centimetres, metres and kilograms prior to analysis. Measurements were taken by two research assistants who were trained in a standard protocol for measurement to achieve consistency in 
measurement once per year throughout the course of the study. Body mass index was calculated using the formula: body mass $(\mathrm{kg}) /$ height $\left(\mathrm{m}^{2}\right)$.

(ii) Preferences for, and use of, peripheral computer equipment: A questionnaire developed for the study that identify which peripheral notebook computer equipment, if any, the participants consistently used; their preferences for the type of equipment used; comfort levels, and hours typically spent at the computer. Participants completed this questionnaire at the commencement of the study in October 2009.

(iii) Typing speed and accuracy: Participants were timed while typing a paragraph through an online program (www.typingmaster.com; TypingMaster, Inc.). Net and gross typing speeds and accuracy were measured by the program. The typing test was administered under the supervision of the research team during data collection at the beginning and end of each academic year during the study.

(iv) Musculoskeletal comfort and discomfort experienced during computer use: (i) The Young people's Activity Questionnaire (YAQ), developed by researchers at Curtin University of Technology, Perth, Australia, was placed online for this study at www.ergonomicsfortherapists.com. The YAQ was used to record participants' demographic information and document physical and behavioral change, and discomfort associated with computer use. The participants completed the YAQ twice per year during the study.

(v) Vision and visual complaints: Participants received bi-annual vision examinations that assessed distance acuity, near acuity, and contrast. The vision examination also documented the student's self-reported symptoms of visual discomfort (e.g. dry or 
watery eyes, itchy eyes, redness) while using the notebook computer, through the use of a checklist. The vision examination was conducted by a member of the research team, an occupational therapist who specializes in visual impairments.

Other methods of data collection, including computer monitoring software and photographs of participants using their notebook computers in their home environment, will not be reported in this paper.

\section{STATISTICAL ANALYSES}

Standard descriptive statistics (means and standard deviations) were used to summarize the height, weight and body mass index (BMI) of the study participants at each of the data collection time points. A repeated measures ANOVA (implemented as a random effects regression model) was used to identify the statistical significance of any changes in these continuous variables over the course of the study. The same modeling approach was used to identify the significance of any changes in typing speed and accuracy over time. Statistical significance of pairwise differences between means at different time points was assessed from the regression model.

The discomfort outcomes of back-pain, headache and neck/shoulder pain were documented (as present or absent) and a general estimating equation (GEE) used to identify the statistical significance of any changes in these binary variables over time. The GEE model is similar to a Logistic Regression, except that it takes into account any correlation between results belonging to the same individual over time. In this sense, it may be considered as a 'repeated measures logistic regression'. The influence of any other factors which may have been expected to influence these discomfort outcomes 
(including the type of keyboard) was assessed by introducing terms into the GEE model representing these variables.

Simple correlation coefficients (Spearman's) were calculated to assess the association between musculoskeletal discomfort and use of computer peripheral accessories (i.e. external keyboard, mouse, notebook riser riser), and location of computer use (e.g. desk, floor, bed), at each time period separately.

For all statistical tests, a p-value $<0.05$ was taken to indicate a statistically significant difference or association. Statistical analyses were carried out using the SAS statistical software package (SAS version 9.2, SAS Institute Inc. Cary, NC, USA, 2008).

\section{RESULTS}

\subsection{Participant demographics}

At baseline (T1 - October 2009), 34 students (58\% males; $42 \%$ females) in $7^{\text {th }}$ grade at one public middle school located in a homogenous, affluent suburb in Maine, USA participated in the study. The following year, data were collected twice when students were in $8^{\text {th }}$ grade (T2 May 2010 with 26 students participating and T3 October 2010 with 23 students participating.

After graduating from middle school, the participants entered $9^{\text {th }}$ grade and started their coursework at the public high school located in the same school district as the middle school. Data were collected once when participants were in $9^{\text {th }}$ grade; at T5 (October 2011) with 23 participants. Attrition throughout the three years occurred for a number of reasons: some students moved from the school district, there was a lack of 
interest in the study by some participants, and some participants were absent when the researchers collected data. The out-of-state research team travelled to Maine once during each data collection time period and so the opportunity to return to collect data from absent students was limited.

The mean height $(\mathrm{cm})$, body mass $(\mathrm{kg})$ and BMI $\left(\mathrm{kg} / \mathrm{m}^{2}\right)$ of the participants across the five time periods are shown in Table 1.

\section{INSERT TABLE 1 HERE}

The random effects regression model identified significant changes in height $(p<0.001)$, weight $(p<0.001)$ and BMI $(p<0.001)$. The statistical significances of pairwise differences are shown in Table 2. Significant changes in height and weight occurred at all time periods, except that there was no change between the final two surveys (T4 to T5). Body Mass Index also showed significant changes up to the second year of the study, but no change from that point onwards.

\subsection{Typing speed and accuracy}

The participants' mean (SD) typing speed (words per minute- wpm) and accuracy (expressed as a per cent of the number of words typed correctly divided by the total number of words typed) in each of the time periods is shown in Table 2.

INSERT TABLE 2 HERE

The random effects regression model identified significant changes in net typing speed $(p<0.0001)$, gross typing speed $(p<0.0001)$ and typing accuracy $(p=0.006)$ across the five time points (as shown in Table 2). Net and gross typing speed improved 
significantly across all time periods except for T3 to T4. Typing accuracy was

significantly better in the final time period (T5) than each of the other periods. When variables indicating back-pain, headache and neck/shoulder pain were introduced into the regression models, they showed no significant association with typing accuracy or speed (net or gross).

\subsection{Physical discomfort}

The GEE models showed that there was a significant drop in neck/shoulder pain over the course of the study, but no significant change in the other discomfort/pain endpoints. Neck/shoulder pain appeared to affect the majority of participants at baseline (76\%), but that proportion reduced significantly over the subsequent 3 years of the study (see Table 3).

\section{INSERT TABLE 3 HERE}

When these GEE models were extended to include a term for the type of keyboard used (split or non-split), there was found to be no significant association between this variable and any of the outcomes (numbers and percentages, along with p-values to compare keyboard type are shown in Table 3).

\subsection{Visual complaints}


Table 4 shows the number (\%) of students at each time period who reported experiencing visual complaints. The GEE model showed that there were no significant changes in reported blurred near vision across time periods $(p=0.691)$, blurred distance vision ( $p=0.750)$, sore and tired eyes $(p=0.077)$, burning itching or redness $(p=0.996)$, light sensitivity $(p=0.350)$, or dry and watery eyes $(p=0.054)$.

INSERT TABLE 5 HERE

\subsection{Musculoskeletal discomforts and notebook computer use with peripheral accessories}

In order to investigate the possible influence of peripheral accessories on the reporting of musculoskeletal discomforts, variables indicating the type of accessory in use (external keyboard or mouse), were added into the GEE models. This showed that use of an external keyboard was significantly associated with neck/shoulder pain (Odds Ratio: $0.23 ; 95 \% \mathrm{Cl}: 0.05$ to $0.95 ; p=0.043)$, so that participants who used this device were less likely to report neck/shoulder pain (after adjustment for the year of data collection).

Although the numbers of participants in each time period were small, the association between peripheral accessory use and each of the musculoskeletal discomforts was also assessed within each year separately, by examining the Spearman's correlation coefficients. The purpose of this analysis was to identify if associations appeared within certain years only, or across several time periods. 
Consistent with the overall results above (from the GEE model), at T2 (May 2010), using an external keyboard was moderately and negatively correlated with neck and shoulder discomfort $\left(r_{s}=-0.527, p=0.006\right)$. Using a mouse was also found to be moderately and negatively correlated with headaches $\left(r_{s}=-0.584, p=0.002\right)$ at T2. At T4, using no accessories was moderately and positively correlated with back pain $\left(r_{s}=\right.$ $0.514, p=0.020)$. A larger sample size would be required to establish the strength of these relationships, as the small sample in the current study was only able to identify associations with large effect sizes.

\subsection{Musculoskeletal discomforts and location of notebook computer use}

The locations that participants reported using their notebook computers included the desk, floor, table, bed, and other. During T1 (October 2009), the majority of participants (65\%) self-reported using their notebook computers at a table; at the desk (54\%); the bed (23\%); the floor (23\%) and other (19\%). In all subsequent times, the majority of participants self-reported using their notebook computers at a desk (i.e. May 2010-54\%; October 2010-76\%; and May 2011-74\%).

Variables indicating the location of laptop use were introduced into the GEE models for the musculoskeletal discomforts, but none were found to be significantly associated with any of these dependent variables (headache, neck/shoulder discomfort, back pain). As before, data from each year were examined separately using the Spearman's correlation coefficient. At T2, using the notebook at a desk was moderately and negatively correlated with back pain $\left(r_{s}=-0.553, p=0.009\right)$. At T5, using the notebook on a bed moderately and positively correlated with headaches $\left(r_{s}=-0.611\right.$, 
$p=0.041)$ and back pain $\left(r_{s}=0.611, p=0.041\right)$. There were no other significant associations between location of notebook use and reported musculoskeletal discomforts.

\subsection{DISCUSSION}

The school children in this study grew significantly taller and heavier as they aged from the beginning of the study in October 2009 until October 2010, when no further significant change in height or weight was observed. The children's BMI measurements across the five time periods were all within the healthy range, adjusted for age and gender [29].

The students' net and gross typing speeds improved significantly across time periods during notebook exposure in the MLTI, suggesting they were becoming more proficient in the use of the technology. Typing proficiency expectations for school students vary across educational jurisdictions in the USA and internationally, and there is not consistent evidence in ergonomics research literature to identify typical typing speed and accuracy among children and adolescents, stratified by age. The students in our study demonstrated by the third year of the involvement in the MLTI, mean typing speeds similar to the teens reported in a prior study [21] who were considered to be touch typists. This suggests that regardless of whether the students in our study are classified as touch typists or not, they are not likely to be considered "hunt and peck" typists. Prior researchers have proposed that typing proficiency is associated with lower ergonomic risks and associated musculoskeletal complaints among child computer 
users [10, 21]; however, we found no association between typing proficiency and reported musculoskeletal discomfort in our study.

The prevalence of neck and shoulder pain among our study participants significantly decreased over the duration of the first three years of this longitudinal study; however, we were unable to identify any one specific reason for this. The provision of peripheral accessories such as an external keyboard, mouse and notebook riser has been recommended by others [15]. These accessories appeared to provide health benefits of the students in our study with the use of peripheral notebook accessories generally associated with less musculoskeletal discomfort and headaches; however, our findings require confirmation in a larger sample.

A review of 35 years of empirical ergonomics evidence investigating split geometry keyboards compared to the standard QWERTY keyboard concluded that there are health benefits to the alternative split design [30]. Reduced musculoskeletal discomfort is most likely associated with less awkward postures and lower tissue loads of the hands/wrist when using the split design keyboards; although, benefits are more likely seen among touch typists and at least a four-month durations of use was required before significant reduction in pain symptoms could be identified [31]. With regard to the benefits of the split vs. non-split external keyboard used as an accessory to the notebook in our study, we found no difference in associated discomfort based on keyboard design; suggesting either external keyboard can have health benefits. It is important to note however, that the portability afforded by notebook technology means that when away from the classroom, students can use the notebook in different locations, such as the floor or bed [5, 32], that do not support the use of accessories, 
and which may involve non-neutral postures of the head/neck and low back that have been associated with discomfort among computer users [5].

The visual complaints most often reported by participants in our study were sore, tired eyes ( $48 \%$ of respondents at T1), and dry or watery eyes ( $48 \%$ of respondents at T1) These symptoms have been previously reported in studies of child and adolescent computer users [14] and often occur because of reduced blink rate leading to greater tear evaporation over the eye and drier eyes [33]. Engagement in computer-based activities that hold the child's attention and insufficient self-regulation of time of task can result in sustained periods of lessened blinking and staring at the screen. We did find a trend for reduction in the prevalence of these symptoms across time periods in our study, suggesting study participants became better at self-regulation of visual tasks based on the recommendations provided in the ergonomics education program.

There are some limitations to our study design that should be noted. The study sample was homogenous in regard to socio-demographic factors; they were all from a single public school located in a homogenous, affluent suburb in Maine. Small size and homogeneity of the sample limits the external validity of the study's findings to children from other socio-economic groups.

Constant reinforcement of the study requirements and reminders to participants by the researchers assisted in maintaining participant compliance; however, the study design was very labor intensive for both participants and the researchers. This likely contributed to the attrition of some participants after the first year of the study. The 
resultant small sample size poses a threat to the internal validity of the study and the possible presence of Type II errors.

\subsection{CONCLUSION}

This study aimed to investigate reported musculoskeletal discomfort and visual complaints among students participating in the Main Learning Technology Initiative who received ergonomics education and equipment to promote healthy notebook

computing. This longitudinal study was initiated in 2009, with $347^{\text {th }}$ grade students consenting to participate in an ergonomics education program and provide follow up data every year for six years until they complete the $12^{\text {th }}$ grade. This article reported results from the first three years of the study.

Over the course of the study, the participants' improved their typing speed and accuracy to become as proficient as touch typists. There was a reduction in neck and shoulder discomfort, which may have been in part attributable to use of peripheral notebook accessories including an external keyboard. Location of notebook use was mainly at a desk or table, which may also be associated with the reduction in discomfort. Visual complaints including sore and tired eyes, and dry or watery eyes significantly reduced over time among study participants.

\section{ACKNOWLEDGEMENTS}

[edited for review process]

\section{REFERENCES}


[1]. Harris C, Straker L, Pollock C, Trinidad S. Musculoskeletal outcomes in children using information technology- the need for a specific etiological model. Int $\mathrm{J}$ Ind Ergonom. 2005;35:131-8.

[2]. Ciccarelli M, Straker L, Mathiassen S, Pollock C. ITKids Part 1: A comparison of children's occupations and use of Information and Communication Technologies at and away-from-school. Work. 2011;38(4):401-12.

[3]. Kent N, Facer K. Different worlds? A comparison of young people's home and school ICT use. Journal of Computer Assisted Learning. 2004;20(6):440-55.

[4]. Rideout V, Foehr U, Roberts D. Generation M²: Media in the lives of 8- to 18-yearolds. The Henry J. Kaiser Family Foundation; 2010 [cited 201227 June]; Available from: http://www.kff.org.

[5]. Harris C, Straker L. Survey of physical ergonomics issues associated with school children's' use of laptop computers. Int J Ind Ergonom. 2000;26:337-46.

[6]. Hakala P, Rimpelä A, Saarni L, Salminen J. Frequent computer-related activities increase the risk for neck-shoulder and low back pain in adolescents. Eur J Public Health 2006;16(5):536-41.

[7]. Kelly G, Dockrell S, Galvin R. Computer use in school: Its effect on posture and discomfort in school children. Work. 2008;32:321-8.

[8]. Dockrell S, Fallon E, Kelly M, Masterson B, Shields N. School children's use of computers and teachers' education in computer ergonomics. Ergonomics. 2007 10;50(10):1657-67.

[9]. Tran T, Ciccarelli M. School children's knowledge of, and attitudes towards, healthy computer use. Work. 2012;41:863-8

[10]. Jacobs K, Baker N. The association between children's computer use and musculoskeletal discomfort. Work. 2002;18(3):221-6.

[11]. Williams I. Students' musculoskeletal and visual concerns. XVI Annual International Occupational Ergonomics and Safety Conference2002.

[12]. Harreby M, Neergaard K, Hesselsoe G, Kjer J. Are radiologic changes in the thoracic and lumbar spine of adolescents risk factors for low back pain in adults? A 25-year prospective cohort study of 640 school children. Spine. 1995;20(21):2298302.

[13]. Von Stroh R. Computer vision syndrome. Occupational Health \& Safety. 1993;62(10):62-5.

[14]. Yan Z, Hu L, Chen H, Lu F. Computer vision syndrome: A widely spreading but largely unknown epidemic among computer users. Comput Hum Behav. 2008;24(5):2026-42.

[15]. Berkhout AL, Hendriksson-Larsén K, Bongers $P$. The effect of using a laptopstation compared to using a standard laptop PC on the cervical spine torque, perceived strain and productivity. App Ergon. 2004;35(2):147-52.

[16]. Sommerich C, Starr H, Smith C, Shivers C. Effects of notebook computer configuration and task on user biomechanics, productivity, and comfort. Int $\mathrm{J}$ Ind Erg. 2002;30(1):7-31.

[17]. Jacobs K, Hudak S, McGiffert J. Computer-related posture and musculoskeletal discomfort in middle school students. Work. 2008;32:275-83. 
[18]. Bali J, Navin N, Thakur. Computer vision syndrome: A study of the knowledge, attitudes and practices in Indian ophthalmologists. Indian $\mathrm{J}$ Ophthalmol. 2007;55(4):289-93.

[19]. Blehm C, Vishnu S, Khattak A, Mitra S, Yee R. Computer vision syndrome: A review. Survey of Ophthalmology. 2005;50(3):253-62.

[20]. Zlamanski R, Ciccarelli M. Do teachers believe they are competent to promote healthy ICT use among their students? Work. 2012;41:869-75

[21]. Kimmerly L, Odell D. Children and computer use in the home: Workstations, behaviors and parental attitudes. Work. 2008;32:299-310.

[22]. Straker L, Maslen B, Burgess-Limerick R, Johnson P, Dennerlein J. Evidencebased guidelines for the wise use of computers by children: Physical development

Guidelines. Ergonomics. 2010;53(4):458-77.

[23]. Mathiassen S. Diversity and variation in biomechanical exposure: What is it, and why would we like to know? Applied Ergonomics. 2006 2006/7;37(4):419-27.

[24]. Ciccarelli M, Straker L, Mathiassen S, Pollock C. ITKids Part II: Variation of postures and muscle activity in children using different Information and Communication Technologies. Work. 2011;38(4):413-28.

[25]. Ciccarelli M, Straker L, Mathiassen S, Pollock C. ITKids Part I: Children's occupations and use of Information and Communication Technologies. Work. 2011 38(4):401-12.

[26]. Chansirinukor W, Dianne Wilson, Grimmer K, Dansie B. Effects of backpacks on students:Measurement of cervical and shoulder posture. Australian Journal of Physiotherapy. 2001;47:110-6.

[27]. Bauer D, Freivalds A. Backpack load limit recommendation for middle school students based on physiological and psychophysical measurements. Work. 2009;32(3):339-50.

[28]. Silvernail D, Lane D. The impact of Maine's One-to-One Laptop Program on middle school teachers and students: Phase One Summary Evidence: Maine Education Policy Research Institute; University of Southern Maine Office2004.

[29]. National Center for Health Statistics. Clinical Growth Charts. Hyattsville, MD. 2009 [cited 201227 July ]; Available from: http://www.cdc.gov/growthcharts/clinical charts.htm.

[30]. Rempel D. The split keyboard: An ergonomics success story. Human Factors. 2008 June 1, 2008;50(3):385-92.

[31]. Tittiranonda P, Rempel D, Armstrong T, Burastero S. Effect of four computer keyboards in computer users with upper extremity musculoskeletal disorders American Journal of Industrial Medicine. 1999;35 647-61.

[32]. Shin H. Musculoskeletal Symptoms and laptop computer use among college students. Pittsburgh: University of Pittsburgh; 2010.

[33]. Kozeis N. Impact of computer use on children's vision. Hippokratia 2009;13 (4):230-1. 


\section{Table Captions}

Table 1. Mean and standard deviation for height, body mass and body mass index $(\mathrm{BMI})$ at each time period; and $\mathrm{p}$-values for pairwise differences obtained from the regression model.

Table 2. Mean and standard deviation for measures of typing proficiency at each time period; and $p$-values for pairwise differences obtained from the regression model.

Table 3. Participants' self-reported musculoskeletal discomforts according to the type of keyboard used (number and per cent), at each time period.

Table 4. Participants' self-reported visual complaints (number and per cent), at each time period. 
Table 1.

\begin{tabular}{|c|c|c|c|c|c|c|}
\hline & \multirow{2}{*}{$\begin{array}{l}\text { Time } \\
\text { period }^{a}\end{array}$} & \multirow[t]{2}{*}{ Mean (SD) } & \multicolumn{4}{|c|}{ p-values of pairwise differences } \\
\hline & & & T2 & T3 & T4 & T5 \\
\hline \multirow[t]{5}{*}{ Height (cm) } & $\mathrm{T} 1$ & $160.9(6.7)$ & $<0.0001$ & $<0.0001$ & $<0.0001$ & $<0.0001$ \\
\hline & T2 & $166.9(7.3)$ & & 0.0085 & $<0.0001$ & $<0.0001$ \\
\hline & T3 & $169.3(7.2)$ & & & 0.0005 & $<0.0001$ \\
\hline & $\mathrm{T} 4$ & $172.1(7.8)$ & & & & 0.4473 \\
\hline & T5 & $173.2(8.9)$ & & & & \\
\hline Body mass & T1 & $48.5(8.6)$ & $<0.0001$ & $<0.0001$ & $<0.0001$ & $<0.0001$ \\
\hline \multirow[t]{4}{*}{$(\mathrm{kg})$} & $\mathrm{T} 2$ & $55.8(8.1)$ & & $<0.0001$ & $<0.0001$ & $<0.0001$ \\
\hline & T3 & $59.7(8.9)$ & & & 0.0181 & 0.0004 \\
\hline & T4 & $61.0(9.1)$ & & & & 0.2446 \\
\hline & T5 & $62.9(10.7)$ & & & & \\
\hline \multirow[t]{5}{*}{$\mathrm{BMI}\left(\mathrm{kg} / \mathrm{m}^{2}\right)$} & $\mathrm{T} 1$ & $18.7(2.8)$ & $<0.0001$ & $<0.0001$ & $<0.0001$ & $<0.0001$ \\
\hline & $\mathrm{T} 2$ & $20.0(2.6)$ & & 0.0006 & 0.0013 & 0.0001 \\
\hline & T3 & $20.8(2.7)$ & & & 0.9479 & 0.5729 \\
\hline & T4 & $20.6(2.7)$ & & & & 0.5347 \\
\hline & T5 & $20.9(2.8)$ & & & & \\
\hline
\end{tabular}


Table 2

\begin{tabular}{|c|c|c|c|c|c|c|}
\hline & \multirow{2}{*}{$\begin{array}{l}\text { Time } \\
\text { period }^{a}\end{array}$} & \multirow[t]{2}{*}{ Mean (SD) } & \multicolumn{4}{|c|}{ p-values of pairwise differences } \\
\hline & & & T2 & T3 & T4 & T5 \\
\hline Net typing & $\mathrm{T} 1$ & $28(11)$ & 0.0005 & $<0.0001$ & $<0.0001$ & $<0.0001$ \\
\hline \multirow[t]{4}{*}{ Speed (wpm) } & $\mathrm{T} 2$ & $35(13)$ & & 0.0005 & 0.0005 & $<0.0001$ \\
\hline & T3 & $38(15)$ & & & 0.3559 & 0.0001 \\
\hline & T4 & $40(16)$ & & & & 0.0273 \\
\hline & T5 & $46(16)$ & & & & \\
\hline \multirow{5}{*}{$\begin{array}{l}\text { Gross speed } \\
\text { (wpm) }\end{array}$} & T1 & $31(11)$ & $<0.0001$ & $<0.0001$ & $<0.0001$ & $<0.0001$ \\
\hline & $\mathrm{T} 2$ & $40(14)$ & & 0.0014 & 0.0012 & $<0.0001$ \\
\hline & T3 & $43(13)$ & & & 0.3731 & 0.0012 \\
\hline & $\mathrm{T} 4$ & $44(16)$ & & & & 0.0814 \\
\hline & T5 & $49(15)$ & & & & \\
\hline Accuracy & T1 & $88(7)$ & 0.6135 & 0.6462 & 0.5148 & 0.0013 \\
\hline \multirow[t]{4}{*}{ (\%) } & $\mathrm{T} 2$ & $87(8)$ & & 0.3644 & 0.3194 & 0.0006 \\
\hline & T3 & $88(8)$ & & & 0.7727 & 0.0095 \\
\hline & $\mathrm{T} 4$ & $88(7)$ & & & & 0.0682 \\
\hline & T5 & $91(5)$ & & & & \\
\hline
\end{tabular}


Table 3

\begin{tabular}{|c|c|c|c|c|c|c|}
\hline $\begin{array}{l}\text { Discomfort (body } \\
\text { location) }\end{array}$ & \multicolumn{4}{|c|}{ Time Periods $^{a}$} & \multirow{2}{*}{$\begin{array}{c}\text { T5 } \\
(n=23)\end{array}$} & \multirow[b]{2}{*}{$p$-value } \\
\hline & $\begin{array}{c}\mathrm{T} 1 \\
(\mathrm{n}=34)\end{array}$ & $\begin{array}{c}\text { T2 } \\
(n=26)\end{array}$ & $\begin{array}{c}\text { T3 } \\
(n=24)\end{array}$ & $\begin{array}{c}\text { T4 } \\
(n=21)\end{array}$ & & \\
\hline Back & $13(52 \%)$ & $8(31 \%)$ & $4(17 \%)$ & $3(15 \%)$ & $4(17 \%)$ & 0.1365 \\
\hline Keyboard $^{c}$ & & & & & & 0.2273 \\
\hline Split & $5(38 \%)$ & $5(42 \%)$ & $2(17 \%)$ & $1(11 \%)$ & $3(30 \%)$ & \\
\hline Non-split & $5(71 \%)$ & $2(20 \%)$ & 0 & $2(20 \%)$ & $1(10 \%)$ & \\
\hline $\begin{array}{l}\text { Neck and } \\
\text { shoulder }\end{array}$ & $19(76 \%)$ & $15(58 \%)$ & $5(21 \%)$ & $3(15 \%)$ & $7(30 \%)$ & 0.0013 \\
\hline Keyboard $^{c}$ & & & & & & 0.8085 \\
\hline Split & $9(69 \%)$ & $9(75 \%)$ & $1(8 \%)$ & 0 & $2(20 \%)$ & \\
\hline Non-split & $6(86 \%)$ & $4(40 \%)$ & $2(25 \%)$ & $3(30 \%)$ & $3(30 \%)$ & \\
\hline Headache & $5(20 \%)$ & 7 (27\%) & 0 & $4(19 \%)$ & $3(13 \%)$ & 0.7676 \\
\hline Keyboard $^{c}$ & & & & & & 0.1722 \\
\hline Split & $2(15 \%)$ & $5(42 \%)$ & 0 & $2(22 \%)$ & $2(20 \%)$ & \\
\hline Non-split & $1(14 \%)$ & $1(10 \%)$ & 0 & $2(20 \%)$ & $1(10 \%)$ & \\
\hline${ }^{\mathrm{a}}(\mathrm{T} 1=$ October 200 & $\mathrm{T} 2=$ May 2 & $10 ; \mathrm{T3}=$ Octc & ober 2010; & $=$ May 2011; & $\overline{5}=$ October 2 & \\
\hline
\end{tabular}


Table 4.

\begin{tabular}{|c|c|c|c|c|c|c|}
\hline & $\begin{array}{c}\mathrm{T}^{\mathrm{a}} \\
(\mathrm{n}=34)\end{array}$ & $\begin{array}{c}\text { T2 } \\
(n=26)\end{array}$ & $\begin{array}{c}\text { T3 } \\
(n=24)\end{array}$ & $\begin{array}{c}\text { T4 } \\
(n=21)\end{array}$ & $\begin{array}{c}\text { T5 } \\
(n=23)\end{array}$ & $p$-value \\
\hline Blurred near vision & $6(24 \%)$ & $5(19 \%)$ & $3(13 \%)$ & $3(15 \%)$ & $2(9 \%)$ & 0.691 \\
\hline $\begin{array}{l}\text { Blurred distance } \\
\text { vision }\end{array}$ & $2(8 \%)$ & $1(4 \%)$ & 0 & 0 & $2(9 \%)$ & 0.750 \\
\hline Sore/tired eyes & $12(48 \%)$ & $13(50 \%)$ & $8(33 \%)$ & $8(40 \%)$ & $5(22 \%)$ & 0.077 \\
\hline Dry/watery eyes & $12(48 \%)$ & 5 (19\%) & $3(13 \%)$ & $4(20 \%)$ & $2(9 \%)$ & 0.054 \\
\hline $\begin{array}{l}\text { Burning/itching } \\
\text { redness }\end{array}$ & $2(8 \%)$ & $2(8 \%)$ & $2(8 \%)$ & 0 & 0 & 0.996 \\
\hline
\end{tabular}




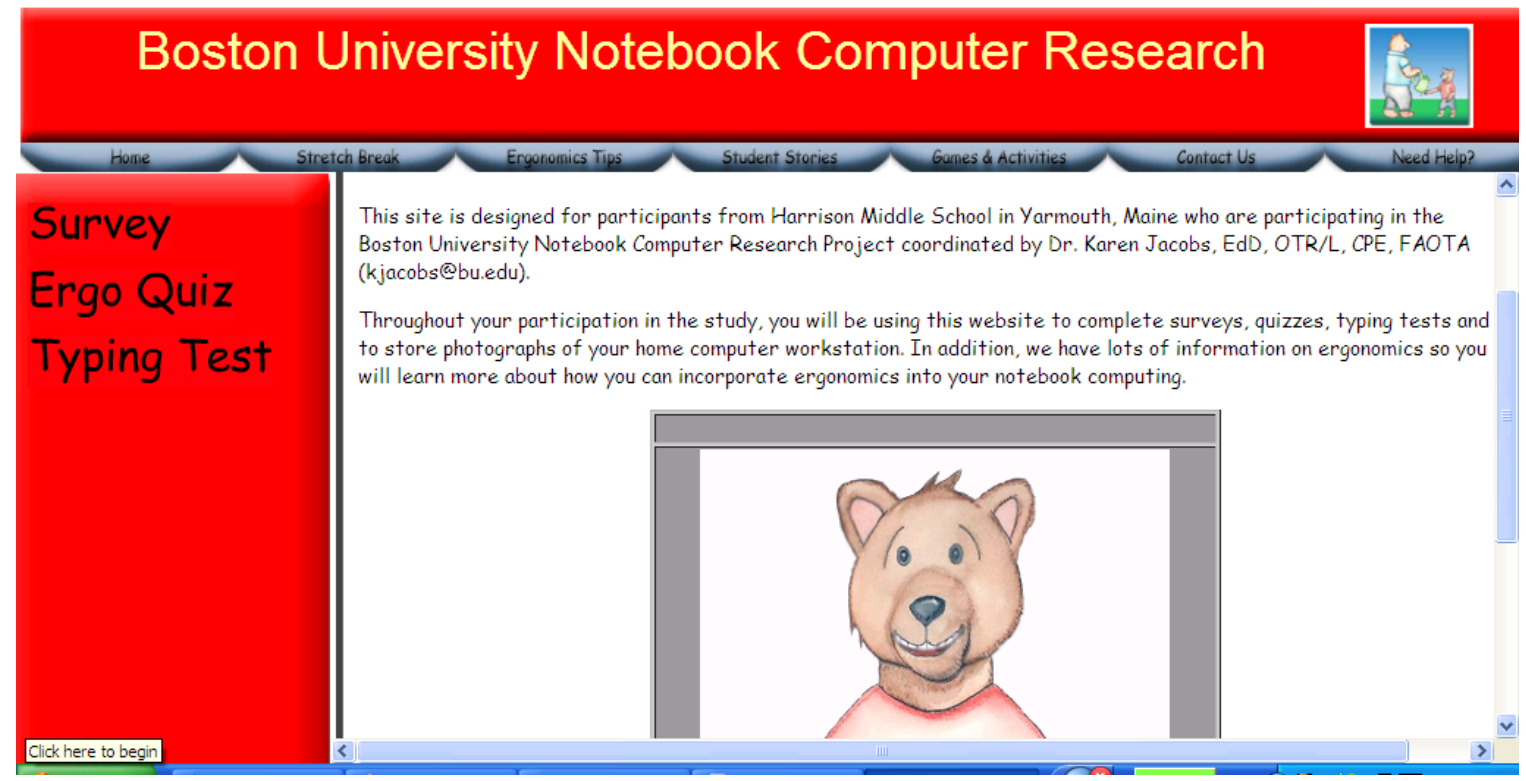

Figure 1: Home Page of Participatory Ergonomic Training Reinforce through Web Based Education 